\title{
PROFIL AKNE VULGARIS DI RSUP Prof. Dr. R. D. KANDOU MANADO PERIODE 2009-2011
}

\author{
${ }^{1}$ Muhammad Mizwar \\ ${ }^{2}$ Marlyn Grace Kapantow \\ ${ }^{3}$ Pieter Levinus Suling
}

\author{
Bagian Ilmu Kesehatan Kulit dan Kelamin Fakultas Kedokteran Universitas Sam \\ Ratulangi Manado \\ Email: mizuogan123@gmail.com
}

\begin{abstract}
Acne vulgaris is a chronic inflammatory disease of pilosebaceous follicles that commonly occurs in adolescence and can heal itself. The purpose of this study was to determine the profile of acne vulgaris in Dermatovenereology of Prof. Dr. R. D. Kandou Manado in 2009-2011. This study was conducted retrospectively in patients with acne vulgaris who came to the Dermatology clinic in 2009-2011. The data were recorded from medical records of the amounts of patients, gender, age, occupation / education, lesion location, and the type of acne. The results showed that of a total of 10003 visits in 2009-2011 there of 121 patients (3.59\%) were new cases of acne vulgaris, acne vulgaris in patients dominance of female patients by 75 patients (61.9\%), the age group most at $15-24$ years old is 76 patients $(62.8 \%)$, the highest educational status on the student group is 73 patients $(60.3 \%)$, the most lesions location are on the face, most types of acne is papulopustular. Key words: acne vulgaris, inflammation, pilosebaceous
\end{abstract}

\begin{abstract}
Abstrak: Akne vulgaris adalah penyakit peradangan menahun folikel pilosebasea yang umumnya terjadi pada masa remaja dan dapat sembuh sendiri. Tujuan dari penelitian ini untuk mengetahui profil akne vulgaris di poliklinik Kulit dan Kelamin RSUP Prof Dr R. D. Kandou Manado pada tahun 2009-2011. Penelitian ini dilakukan secara retrospektif pada pasien dengan akne vulgaris yang datang ke poliklinik Kulit dan Kelamin pada tahun 2009-2011. Dilakukan pencatatan data dari catatan medik mengenai jumlah pasien, jenis kelamin, usia, pekerjaan/pendidikan, lokasi lesi, dan jenis akne. Hasil yang diperoleh menunjukkan bahwadari total 10003 kunjungan pada tahun 2009-2011 terdapat 121 pasien $(3,59 \%)$ merupakan penderita baru akne vulgaris, pasien akne vulgaris di dominasi pasien perempuan sebanyak 75 pasien $(61,9 \%)$, kelompok usia terbanyak pada usia 15 - 24 tahun yaitu 76 pasien $(62,8 \%)$, status pendidikan terbanyak pada kelompok pelajar yaitu 73 pasien $(60,3 \%)$, lokasi lesi terbanyak yaitu di bagian wajah, jenis akne terbanyak yaitu papulopustuler.
\end{abstract}

Kata kunci: akne vulgaris, pilosebasea, radang 
Akne vulgaris adalah penyakit peradangan menahun folikel pilosebasea yang umumnya terjadi pada masa remaja dan dapat sembuh sendiri. Gambaran klinis akne vulgaris sering polimorfi; terdiri atas berbagai kelainan kulit berupa komedo, papul, pustul, nodus, dan jaringan parut yang terjadi akibat kelainan aktif tersebut, baik jaringan parut yang hipotrofik maupun yang hipertrofik. $^{1}$

Akne adalah penyakit yang paling umum yang mempengaruhi semua kelompok etnis dan merupakan diagnosis dermatologi terbanyak dengan 10,2 juta diagnosa $(25,4 \%$ dari 10 yang dari diagnosis dermatologi secara umum). ${ }^{2}$ Selama masa remaja, akne vulgaris lebih sering terjadi pada laki-laki daripada perempuan. Pada usia dewasa, akne vulgaris lebih sering terjadi pada wanita dibandingkan pria. $^{3}$ Di Australia, akne ditemukan pada $27,7 \%$ dari siswa berusia $10-12$ tahun dan $93,3 \%$ dari 16-18 tahun. sebuah penelitian di Peru menunjukkan bahwa prevalensi akne pada usia 12 tahun dan 17 tahun adalah 16,33\% dan $71,23 \% .^{4}$ Adapun penelitian yang dilakukan oleh Adityan B di tahun 2006-2008 di India, dari 28.917 pasien, terdapat 309 pasien akne vulgaris dengan frekuensi 1,068\%. Dari 309 pasien, 137 $(44,3 \%)$ adalah perempuan dan 172 $(55,7 \%)$ adalah laki-laki. ${ }^{5}$ Penelitian yang dilakukan oleh Uguy pada bulan oktober di SMU Kristen YPK Manado dengan subjek penelitian murid - murid kelas 1 dan 2 tahun ajaran 2003-2004 yang berjumlah 307 murid, didapatkan bahwa $70,68 \%$ murid menderita akne. ${ }^{6}$ Penelitian lain yang dilakukan oleh Pondaag di Poliklinik RSUP Prof. dr. R. D. Kandou Manado periode 2003
- 2005 didapatkan jumlah pasien sebanyak 145 pasien $(1,24 \%)$ dari total pasien $1165 .^{7}$

Akne vulgaris menjadi masalah kosmetika dan psikologi umum yang terutama terjadi pada kalangan remaja. Meskipun tidak mengancam jiwa, akne memiliki dampak psikososial yang signifikan pada penderita. Rendah diri, penarikan sosial, frustasi, kecemasan, kemarahan, depresi, dan bunuh diri mungkin berkembang sebagai akibat dari akne. Rasa malu dan selfconsciuousness secara langsung berhubungan dengan citra diri dan kepercayaan diri. Rasa malu menjadi lebih bermakna pada individu yang memiliki akne dan pada akhirnya akan menimbulkan rasa cemas, depresi dan yang disforik. Perasaan ini juga berhubungan dengan ketakutan wajah mereka akan diejek oleh orang lain. ${ }^{8-10}$

Berdasarkan uraian di atas, maka hal ini mendorong penulis untuk melakukan penelitian deskriptif retrospektif mengenai profil akne vulgaris di Poliklinik Kulit dan Kelamin RSUP Prof. dr. R. D. Kandou Manado periode 20092011.

\section{METODE PENELITIAN}

Penelitian ini adalah jenis deskriptif retrospektif yaitu mendeskripsikan beberapa faktor dari subjek penelitian yang telah ada dan secara retrospektif dengan menggunakan data subjek penelitian yang diambil dari rekam medik. Penelitian ini dilakukan pada bulan November 2012 sampai Desember 2012. Penelitian ini dilaksanakan di Poliklinik Kulit dan Kelamin RSUP Prof. dr. R. D. Kandou dan bagian rekam medik. Variabel penelitian 
yaitu jumlah kasus per tahun, jenis kelamin, usia, pekerjaan/pendidikan, lokasi lesi, dan jenis akne. Populasi penelitian yaitu semua catatan rekam medik pasien yang berobat di Poliklinik Kulit dan Kelamin RSUP Prof. dr. R. D. Kandou Manado periode 2009-2011. Sampel penelitian yaitu semua catatan medik pasien baru yang didiagnosis akne vulgaris di Poliklinik Kulit dan Kelamin RSUP Prof. dr. R. D.
Kandou Manado periode 2009 2011.

\section{HASIL PENELITIAN}

Berdasarkan penelitian retrospektif yang dilakukan di bagian Kulit dan Kelamin serta Rekam Medik RSUP Prof. dr. R. D. Kandou Manado tentang profil akne vulgaris periode 2009 sampai 2011 maka hasil penelitian tersebut disajikan dalam bentuk tabel sebagai berikut :

Tabel 1. Jumlah kasus per tahun

\begin{tabular}{cccc}
\hline Tahun & Total Pasien & $\begin{array}{c}\text { Jumlah Pasien } \\
\text { Akne Vulgaris }\end{array}$ & Presentase (\%) \\
\hline 2009 & 3306 & 34 & 1,02 \\
2010 & 3452 & 52 & 1,50 \\
2011 & 3245 & 35 & 1,07 \\
\hline Total & 10003 & 121 & 3,59 \\
\hline
\end{tabular}

Tabel 1 meunjukkan jumlah pasien akne vulgaris sebanyak 121 pasien dan jumlah terbanyak pada tahun 2010 yaitu 52 pasien $(1,50 \%)$.

Tabel 2. Distribusi kasus pada divisi kosmetik

\begin{tabular}{cccc}
\hline Tahun & Total Pasien & $\begin{array}{c}\text { Jumlah Pasien } \\
\text { Akne Vulgaris }\end{array}$ & Presentase (\%) \\
\hline 2009 & 164 & 34 & 20,73 \\
2010 & 173 & 52 & 30,06 \\
2011 & 106 & 35 & 33,01 \\
\hline Total & 443 & 121 & 83,8 \\
\hline
\end{tabular}

Tabel 2 menunjukkan akne vulgaris terbanyak pada tahun 2011 yaitu 35 pasien $(33,01 \%)$.

Tabel 3. Distribusi berdasarkan jenis kelamin

\begin{tabular}{ccc}
\hline Jenis Kelamin & Jumlah & Presentase (\%) \\
\hline Laki-laki & 46 & 38,1 \\
Perempuan & 75 & 61,9 \\
\hline Total & 121 & 100 \\
\hline
\end{tabular}

Tabel 3 didapatkan jumlah pasien laki-laki sebanyak $46(38,1 \%)$ dan pasien perempuan sebanyak $75(61,9 \%)$. 
Tabel 4. Distribusi berdasarkan usia

\begin{tabular}{ccc}
\hline Usia (tahun) & Jumlah & Presentase (\%) \\
\hline $10-14$ & 11 & 9,1 \\
$15-24$ & 76 & 62,8 \\
$25-34$ & 23 & 19,1 \\
$35-44$ & 6 & 4,9 \\
$\geq 45$ & 5 & 4,1 \\
\hline Total & 121 & 100 \\
\hline
\end{tabular}

Tabel 4 menunjukkan bahwa jumlah terbanyak pada usia $15-24$ tahun sebanyak 76 pasien $(62,8 \%)$.

Tabel 5. Distribusi berdasarkan pekerjaan

\begin{tabular}{ccc}
\hline Pekerjaan & Jumlah & Presentase (\%) \\
\hline Pelajar & 73 & 60,3 \\
Swasta & 20 & 16,5 \\
PNS & 17 & 14,1 \\
Lain-lain & 11 & 9,1 \\
\hline Total & 121 & 100 \\
\hline
\end{tabular}

Tabel 5 didapatkan pekerjaan pelajar yang paling terbanyak yaitu sebanyak 73 pasien (60,3\%), swasta sebanyak 20 pasien (16,5\%), PNS sebanyak 17 pasien $(14,1 \%)$ dan lain-lain sebanyak 11 pasien $(9,1 \%)$.

Tabel 6. Distribusi berdasarkan lokasi lesi

\begin{tabular}{ccc}
\hline Lesi & Jumlah & Presentase (\%) \\
\hline Wajah & 112 & 92,5 \\
Dada, punggung, lengan atas & 3 & 2,5 \\
Kombinasi & 6 & 5 \\
\hline Total & 121 & 100
\end{tabular}

Tabel 6 didapatkan lesi terbanyak terdapat pada wajah yaitu 112 pasien $(92,5 \%)$.

Tabel 7. Distribusi berdasarkan klasifikasi

\begin{tabular}{ccc}
\hline Jenis Akne & Jumlah & Presentase (\%) \\
\hline Komedonal & 5 & 4,1 \\
Papulopustular & 114 & 94,2 \\
Konglobata & 2 & 1,7 \\
\hline Total & 121 & 100 \\
\hline
\end{tabular}


Tabel 7 didapatkan jenis akne terbanyak yaitu akne papulopustuler sebanyak 114 pasien $(94,2 \%)$.

\section{PEMBAHASAN}

Pada penelitian ini didapatkan jumlah pasien akne vulagris yang berobat ke Poliklinik Kulit dan Kelamin RSUP Prof. dr. R. D. Kandou Manado periode 2009 sampai 2011 sebanyak 121 pasien $(3,59 \%)$.

Pada tahun 2009 terdapat terdapat 34 pasien $(1,02 \%)$ dan kemudian meningkat pada tahun 2010 menjadi 52 pasien $(1,50 \%)$ bahkan merupakan jumlah terbanyak selama tiga tahun. Dan pada tahun 2011, jumlah pasien akne vulgaris kembali menurun menjadi 35 pasien $(1,07 \%)$ (Tabel 1). Adanya penurunan ini kemungkinan tidak semua pasien akne vulgaris berobat ke Poliklinik Kulit dan Kelamin RSUP Manado, tetapi lebih memilih ke dokter praktek pribadi, klinik swasta, dan lain-lain. Dibandingakan dengan divisi kosmetik, pasien akne vulgaris dari tahun 2009 sampai 2011 lebih tinggi, yakni 83,8\% (Tabel 2).

Pada wanita lebih banyak mengalami akne vulgaris yaitu 75 pasien $(61,9 \%)$ dibandingkan dengan laki - laki yaitu 46 pasien $(38,1 \%)$ (Tabel 3$)$. Hal ini bertolak belakang dengan penelitian yang dilakukan oleh Tjekyan, yaitu didapatkan jumlah pasien laki-laki $(37,3 \%)$ lebih tinggi dari perempuan $(30,9 \%) .{ }^{10}$ Namun hasil yang didapatkan sama dengan penelitian yang dilakukan sebelumnya oleh Pondaag di Poliklinik RSUP Prof. Dr. R. D. Kandou Manado periode 2003 2005 didapatkan 77 pasien $(53,1 \%)$ perempuan dan $68(46,9 \%)$ pasien laki laki. ${ }^{7}$ Hal ini diduga disebabkan karena perempuan lebih memperhatikan faktor penampilan sehingga lebih mendorong perempuan untuk datang berobat. Selain itu, bahan-bahan kimia yang ada dalam kosmetik dapat langsung menyebabkan akne vulgaris. Biasanya kosmetik ini menyebabkan akne dalam bentuk ringan terutama komedo tertutup dengan beberapa lesi papulopustul di daerah pipi dan dagu. Hal ini sesuai dengan tinjauan pustaka bahwa jenis kosmetik perawatan seperti pelembab, krim penahan sinar matahari, dan krim malam dapat menyebabkan timbulnya akne vulgaris. $^{10,11}$

Pada penelitian ini, pasien paling banyak selama periode 2009 sampai 2011 adalah kelompok usia 15 - 24 tahun, yakni 76 pasien $(62,8 \%)$ (Tabel 4$)$. Data yang didapatkan sama dengan penelitian sebelumnya yang dilakukan Pondaag di Poliklinik RSUP Prof. Dr. R. D. Kandou Manado periode 2003 - 2005 yaitu terbanyak pada kelompok usia $15-24$ tahun sebanyak 111 pasien $(76,6 \%)$, namun pada penelitian ini terlihat penurunan dari jumlah pasien yaitu dari 111 pasien $(76,6 \%)$ turun menjadi 76 pasien $(62,8 \%){ }^{7}$ Penelitian ini juga mendapatkan penderita akne vulgaris terbanyak terdapat pada kalangan pelajar yakni 73 pasien $(60,3 \%$ ) (Tabel 5). Hal ini sesuai dengn teori, bahwa akne vulgaris lebih sering terjadi pada masa remaja. ${ }^{4}$ Penelitian sebelumnya yang dilakukan oleh Pondaag di Poliklinik RSUP Prof. Dr. R. D. Kandou Manado periode 2003 2005 juga didapatkan hal serupa, yaitu terbanyak pada kalangan pelajar $(33,8 \%)$ namun mengalami penurunan dari penelitian sebelumnya dan penelitian kali ini. $^{7}$

Sebaran penderita akne vulgaris berdasarkan lokasi lesi didapatkan pada bagian wajah yaitu sebanyak 112 pasien $(92,5 \%)$, lesi di dada, punggung dan lengan atas sebanyak 3 pasien $(2,5 \%)$ dan lesi kombinasi sebanyak 6 pasien (5\%) (Tabel 6). Lesi pada wajah merupakan lesi dengan jumlah terbanyak. Hal ini 
disebabkan kelenjar sebasea lebih banyak terdapat pada wajah, dibandingkan dengan dada, punggung dan lengan. ${ }^{12}$ Penelitian sebelumnya yang dilakukan oleh Pondaag di Poliklinik RSUP Prof. Dr. R. D. Kandou Manado periode 2003 2005 juga didapatkan hal yang sama, yaitu terbanyak pada wajah dengan presentase $84,8 \% .^{7}$ Penelitian oleh Tjekyan juga didapatkan hal yang sama, pasien akne vulgaris dengan lesi di bagian wajah sebesar $85,3 \% .^{10}$

Distribusi akne berdasarkan klasifikasi, didapatkan akne papulopustular dengan pasien terbanyak, yaitu 114 pasien $(94,2 \%)$ (Tabel 7). Hal ini sama dengan penelitian yang dilakukan oleh Pondaag dan Tjekyan yaitu didapatkan pasien dengan akne papulopustular sebanyak $91,7 \%$ dan $35,8 \%$. 7,10

Dibandingkan dengan penelitian sebelumnya yang dilakukan oleh Pondaag di Poliklinik RSUP Prof. Dr. R. D. Kandou Manado periode 2003 - 2005 secara umun, didapatkan hasil yang sama, namun terjadi penurunan jumlah pasien dari 145 pasien pada tahun 2003 - 2005 turun menjadi 121 pasien pada tahun 2009 $-2011.7$

\section{KESIMPULAN}

Dari hasil penelitian tentang profil akne vulgaris yang dilakukan di Poliklinik Kulit dan Kelamin RSUP Manado periode 2009 sampai 2011, dapat disimpulkan sebagai berikut :

1. Angka kejadian akne vulgaris di Poliklinik Kulit dan Kelamin RSUP Manado selama periode tiga tahun yaitu terdapat 121 pasien dari 10.003 pasien $(3,57 \%)$ dengan angka kejadian terbanyak pada tahun 2010 yaitu sebesar $1,50 \%$.

2. Akne vulgaris pada divisi kosmetik tergolong tinggi, yaitu $83,8 \%$.

3. Sebaran akne vulgaris berdasarkan kelompok usia paling banyak pada usia $15-24$ tahun.
4. Sebaran akne vulgaris berdasarkan jenis kelamin terbanyak pada wanita dibandingkan pria.

5. Sebaran akne vulgaris berdasarkan pekerjaan terbanyak pada kalangan pelajar.

6. Sebaran akne vulgaris berdasarkan lokasi lesi terbanyak pada wajah.

7. Sebaran akne vulgaris berdasarkan jenis akne terbanyak yaitu akne papulopustuler.

\section{SARAN}

1. Penting dilakukan penulisan buku registrasi yang lebih baik, untuk mempermudah peneliti dalam proses pengambilan data.

2. Perlu dilakukan penelitian selanjutnya pada populasi yang lebih besar, untuk mendapatkan data prevalensi yang lebih lengkap.

\section{UCAPAN TERIMA KASIH}

Diberikan kepada dr. Nurdjannah J. Niode, SpKK dan dr. Renate $T$. Kandou, $\operatorname{SpKK}(\mathrm{K})$ selaku penguji I dan penguji II dan kepada semua pihak baik secara langsung maupun tidak langsung telah menumbuhkan ide atau gagasan pada penulis sehingga penulis dapat menyelesaikan artikel ini.

\section{DAFTAR PUSTAKA}

1. Wasitaatmadja SM. Akne, Erupsi Akneiformis, Rosasea, Rinofima. Dalam : Djuanda A, Hamzah M, Aisah S, penyunting. Ilmu Penyakit Kulit dan Kelamin. Edisi Keenam. Jakarta: Penerbit Fakultas Kedokteran Indonesia; 2010. hal. 253-60.

2. Fabbrocini G, Padova MPD, Cacciapuoti S, Tosti A. In : Tosti A, Grimes PE, Padova MPD. Color Atlas of Cemichal Peels. Second Edition. Heidelberg. Springer. 2012. p : 95-105. 
3. Fulton J, Eltson DM. Acne Vulgaris. 2012 June 28. [citied 2012 Oct 18]. Available from : http://emedicine.medscape.com/art icle/1069804-overview

4. Shen Y, Wang T, Zhou C, Wang X, Ding X, Tian S,et al . 2012. Prevalence of acne vulgaris in chinese adolescents and adults: a community-based study of 17,345 subjects in six cities. Acta Dermato Venereologica. 92 : 4044.

5. Adityan B, Thappa DM. 2009. Profile acne vulgaris-A hospitalbased study from south india.Indian J Dermatol Venereol Leprol. 75 ; 272-8.

6. Pondaag NPZ. Profil Akne Vulgaris di Poliklinik Kulit dan Kelamin RSUP Prof. dr. R. D. Kandou Manado Periode Januari 2003-Desember 2005. Manado : Karya Tulis Ilmiah Sarjana Kedokteran. 2006.

7. Uguy VOA. Prevalensi Akne dan Faktor-faktor Yang Mempengaruhi Akne Pada Remaja di Manado. Manado : Karya Tulis Ilmiah Sarjana Kedokteran. 2003.

8. Kusumawardhani A, Sudharmono A. 2010. Perasaan selfconsciousness dan rendahnya harga diri dan hubungannya dengan kualitas hidup pasien akne vulgaris. Majalah Kedokteran Indonesia. 60(6) : 263-267.

9. Hon CS, Leok GC. Quality of life issues in acne. In : Chan $\mathrm{C}$, editor. Acne facts and tips for clear skin. Singapore : SNP References; 2005. p. 59-62.

10. Tjekyan RMS. 2008. Kejadian dan faktor resiko akne vulgaris. Media Medika Indonesia. 43 (1), 37-43.

11. Harahap M. Rosasea dan akne vulgaris. Dalam : Harahap M, Rachmah L, Cahanar P, penyunting. Ilmu Penyakit Kulit. Jakarta : Hipokrates; 2000. Hal. $35-45$
12. Knaggs $H$. The biology of the sebaceous gland and pathofisiology of acne. In : Webster GF, Rawlings AV, editors. Acne and its therapy. New York: Informa Healthcare; 2007.p. 9-28. 